\title{
1 Dosimetry and methodology of gamma 2 irradiation for degradation studies on 3 solvent extraction systems
} Bart Verlinden, ${ }^{1,2}$ Peter Zsabka, ${ }^{1}$ Karen Van Hecke, ${ }^{1 *}$ Ken Verguts, ${ }^{1}$ Liviu-Cristian Mihailescu, ${ }^{1}$ Giuseppe Modolo, ${ }^{3}$ Marc Verwerft, ${ }^{1}$ Koen Binnemans ${ }^{2}$ and Thomas Cardinaels ${ }^{1,2}$

${ }^{1}$ Institute for Nuclear Materials Science, Belgian Nuclear Research Center (SCK CEN), B-2400 Mol, Belgium

${ }^{2}$ Department of Chemistry, KU Leuven, B-3001 Leuven, Belgium

${ }^{3}$ Institute of Energy and Climate Research - Nuclear Waste Management and Reactor Safety (IEK-6),

Forschungszentrum Jülich GmbH, D-52428 Jülich, Germany

* Author for correspondence (E-mail: karen.van.hecke@sckcen.be)

Keywords: gamma irradiation, TODGA, solvent extraction, dosimetry

\section{Abstract}

The recycling of minor actinides from dissolved nuclear fuels by hydrometallurgical separation is one challenging strategy for the management of spent fuel. These future separation processes will likely be based on solvent extraction processes in which an organic solvent system (extractant and diluent) will be contacted with highly radioactive aqueous solutions. To establish a separation between different elements in spent nuclear fuel, many extractants have been studied in the past. A particular example is $N, N, N^{\prime}, N^{\prime}$-tetraoctyl diglycolamide (TODGA), which co-extracts lanthanides and actinides from nitric acid solutions into an organic phase (e.g. TODGA in $n$-dodecane). The radiolytic stability of these extractants is crucial, since they will absorb high doses of ionizing radiation during their usage. Worldwide, different gamma irradiation facilities are employed to expose extractants to ionizing radiation and gain insight in their radiation stability. The facilities differ in many ways, such as their environment (pooltype or dry), configuration and gamma sources (often ${ }^{60} \mathrm{Co}$ or spent nuclear fuel). In this paper, a dosimetric assessment is made using different dosimeter systems in a pool-type irradiation facility, which has the advantage to be flexible in its arrangement of ${ }^{60} \mathrm{Co}$ sources. It is shown that Red Perspex dosimeters can be used to accurately characterize this high dose rate gamma irradiation field (approx. $13.6 \mathrm{kGy} \mathrm{h}^{-1}$ ), after comparison with alanine, Fricke and ceric-cerous dosimetry in a lower dose rate gamma irradiation field (approx. $0.5 \mathrm{kGy} \mathrm{h}^{-1}$ ). A final validation 
31 of the whole chain of techniques is obtained by reproduction of the dose constants for TODGA 32 in $n$-dodecane. 


\section{Introduction}

Waste produced by nuclear power plants remains highly radiotoxic for millions of years. Therefore, safe management of long-lived radioactive waste including final long-term storage of the spent nuclear fuel poses a challenge. In spent nuclear fuel, plutonium and the minor actinides are the main contributors of radiotoxicity and heat production on the long term. The size of the necessary final repository is mainly defined by this heat production.[1] To minimize the space required in the deep geological repository, new separation processes for actinides based on liquid-liquid extractions are developed. Here, a separation is obtained by adding an organic phase (e.g. kerosene) with complexing agents to dissolved spent fuel solutions. Initially, the Plutonium Uranium Reduction EXtraction (PUREX) process was developed to recover the major actinides (U and Pu) from spent fuel.[2] In the following decades, more research has been conducted to also recover the minor actinides[3-4] in order to further decrease the long-term activity of the residual spent fuel inventory, which led to developments of new complexing agents or ligands, such as diglycolamides.[5-6] The most important, and up to date, most intensely studied member of this class of ligands is $N, N, N^{\prime}, N^{\prime}$-tetraoctyl diglycolamide (TODGA) of which the structure is shown in Figure 1. As the solvents used in these hydrometallurgical processes need to be operated in contact with radioactive feed solutions, it is crucial to not only evaluate new compounds on their extraction behavior, but to also study how they are affected by ionizing irradiation.

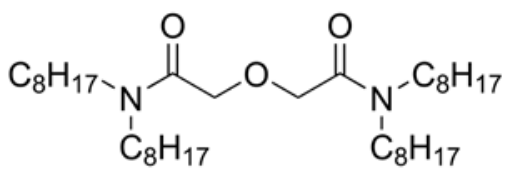

Figure 1: Structure of TODGA.

Radioactive decay causes degradation of the organic phase in different ways. Ionizing radiation can directly cause disintegration of certain bonds of ligand molecules. However, studies on radiolysis of TODGA have shown that its degradation is dominated by reactions with radical cations of the diluent.[7-8]

For the comparison of the radiolytic degradation of different ligands or to study the effect of changing the diluent, dose constants $(d)$ are being used in this research.[9] The dose constant is determined by the slope of the linear fit of the natural logarithm of the concentration of the molecule as a function of the absorbed dose. This slope can be considered as a constant if the degradation exhibits (pseudo) first-order kinetics. The use of the $G$ and $G_{o}$ values in this context was discussed by Mincher et al.[9] The main weakness of the use of $G$ values is that it depends 
on the concentration, which changes in the case of continuous irradiation experiments. For this reason it could be more useful to define $G_{o}$, which is defined as the slope of the concentration as a function of the dose, but only over a very small interval near the initial concentration.[10] In this case, $G_{o}$ is the slope of a line tangent to the curve and it can be expressed as the dose constant multiplied with the initial concentration and converted to the appropriate units $\left(C_{o}\right.$ is the initial concentration in $\mu \mathrm{mol} \mathrm{kg} \mathrm{kg}^{-1}$ ) using equation (1).[9, 11] For simplicity and consistency, in this work only dose constants will be compared.

$$
G_{o}=d \times C_{o}
$$

The ligand TODGA is a well-studied molecule which is known to co-extract actinides and lanthanides efficiently due to the tridentate coordination through hard-donor oxygen atoms.[1214] Its radiolysis behavior has been studied intensively,[15-18] which makes it a usable reference for further radiolysis research of solvent extraction systems.

The gamma sources in previous radiolysis stability studies were either ${ }^{60}$ Co sources,[15, 19-20] or spent nuclear fuel sources.[21-22] The gamma spectrum of the latter is much broader than the spectrum of ${ }^{60} \mathrm{Co}$ because of the presence of different fission and activation products such as ${ }^{137} \mathrm{Cs},{ }^{134} \mathrm{Cs}$, ${ }^{154} \mathrm{Eu}$ and ${ }^{60} \mathrm{Co}$. Furthermore, Bremsstrahlung, which is generated by the deceleration of electrons and positrons in the Coulomb field of nuclei, contributes significantly to the total photon source spectrum of a spent nuclear fuel source. It should be noted that there is also a difference between different ${ }^{60}$ Co sources. Gamma irradiations are either conducted using dry facilities[15, 17-18, 20, 23-25] (e.g. Gammacell 220), or pool-type facilities[16, 19, 26-27] (e.g. Náyade at CIEMAT). In the latter, the spectrum will be degraded because of passing through water and steel.[28] In general, gamma irradiation facilities are used for many purposes: modification of polymers,[29] sterilization in medical applications,[30-31] food preservation[32] and for radiolysis studies on solvents used for reprocessing of spent nuclear fuels.[7, 15-20, 23, 33-38] Also for testing material resistance in general, these facilities prove to be very useful, e.g. for testing of fiber-optics for space industry.[39]

In an experimental pool-type ${ }^{60} \mathrm{Co}$ gamma ray field used for irradiation studies, the complexity of the variable irradiation geometry (number, configuration and activity of the loaded ${ }^{60} \mathrm{Co}$ sources) requires a dosimetric assessment in advance of any experiment. Schematic representations of these irradiation set-ups are shown in Figure 2. It is a great advantage that sources can be added and repositioned to obtain the best possible conditions for certain experiments, although this makes characterization of the irradiation field crucial. The selection 
of suitable dosimetry systems that was used for the assessment, was made on the basis of international recommendations, reviews and standards elaborated for high dose rate field radiation processing facilities.[40-42] Alanine,[41] Fricke[43] and ceric-cerous[44] dosimeters are classified as reference-standard dosimeters (type I), in contrast to Perspex dosimeters which are classified as routine (type II) dosimeters.[41] The advantage of type I dosimeters is that they are of high metrological quality: different quantifiable influences are very well identified and can be compensated by using correction factors. However, application of these involves many manipulations and handling of chemicals, which consume a lot of time and resources. On the other hand, routine type II dosimeters, such as Perspex dosimeters, are easy to use and do not require any preparations, except precise positioning. The disadvantage of this type of dosimeters is that the response is influenced in a complex way for which it is not possible to apply individual correction factors.[41] Responses may vary because of environmental conditions such as temperature, light, relative humidity and the presence of gases.[45] The use of alanine and Fricke dosimetry is limited to low dose rate facilities (in our case $\pm 0.5 \mathrm{kGy} \mathrm{h}^{-1}$ ), since absorbed doses during positioning in high dose rate fields would get too significant for these sensitive dosimeters. An overview of the applicable working ranges (absorbed doses) of all applied dosimeter systems is shown in Figure 3. Here, it can be easily noticed that alanine and Fricke dosimeters are indeed on the low side of the absorbed dose ranges compared to Perspex and ceric-cerous dosimeters. The advantage of ceric-cerous and Fricke dosimetry systems over the others, is that these dosimeters can be tailored to the actual size of the sample to be irradiated, so that the exact geometrical position occupied by the sample to be irradiated can be accurately assessed. Also, these liquid dosimeters have similar absorption properties with respect to gamma radiation as the samples which will be studied (extractant dissolved in an organic diluent). The homogeneity of the used irradiation field is evaluated by mapping the local dose rates of the different sample positions in the sample holder. This information is crucial, since it will be a great asset to use this kind of flexible sources in which the configuration of the sources can be easily modified to the needs of the user.

In this work, the dose constants of TODGA in $n$-dodecane were determined using a pool-type ${ }^{60}$ Co gamma irradiation facility and validated against literature values achieved with dry ${ }^{60} \mathrm{Co}$ sources. The validation of our irradiation methodology posed several challenges. The first challenge was the validation of different dosimeters and the transfer of dose rate calibration from low dose rate gamma fields to high dose rate gamma fields. In this paper, the dosimetric assessment of such a flexible, high dose rate irradiation facility is described in detail. Different 
128 type I dosimeters, of which one is read-out externally, were used to conduct this comparison.

129 The use of various independent methods was chosen in this study to reveal any systematic error 130 that could otherwise remain unnoticed with respect to the dose calibration. Another challenge 131 in this study is the high dose rate gradient due to the close distance to the sources. The final 132 validation of the irradiation set-up for radiolysis studies of solvent extractions systems was 133 performed via chemical analysis of an irradiated well-characterized solvent (TODGA in $n$ 134 dodecane). This study opens perspectives for future research using flexible, high dose rate pool135 type gamma irradiation facilities on novel solvent extraction systems, such as newly developed 136 diglycolamides[19, 46] or ionic-liquid-based systems.[47-49] 


\subsection{Irradiation facilities}

The gamma irradiations were conducted in BRIGITTE (Big Radius Installation under Gamma

140

142

143

144

145

146

147

148

149

\section{0}

151

152

153

154

155

156

157

158

159

160

161

162
A

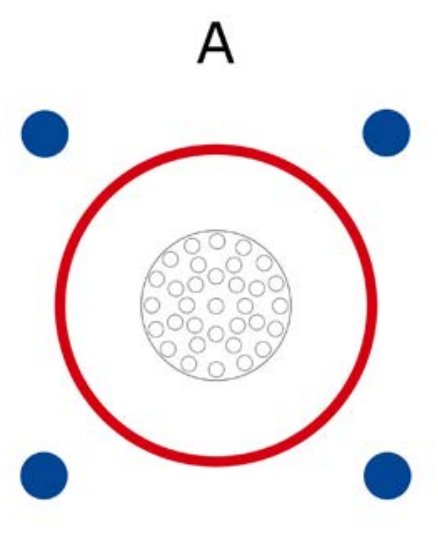

Irtion for Tailoring and Testing Experiments) and RITA (Radio Isotope Test Arrangement) of SCK CEN (Mol, Belgium).[50] Here, underwater (pool-type) ${ }^{60}$ Co sources ( $E_{\gamma 1}=1173.2 \mathrm{keV}$ and $E_{\gamma 2}=1332.5 \mathrm{keV}$ ) are used at an approximate dose rate of respectively $13.6 \mathrm{kGy} \mathrm{h}^{-1}$ (BRIGITTE) and $0.510 \mathrm{kGy} \mathrm{h}^{-1}$ (RITA). These ${ }^{60} \mathrm{Co}$ sources are old control rods of the Belgian Reactor 2 (BR2), where ${ }^{59}$ Co parts were activated during reactor operation. Schematic representations of the set-up in RITA and BRIGITTE are shown in Figure 2.

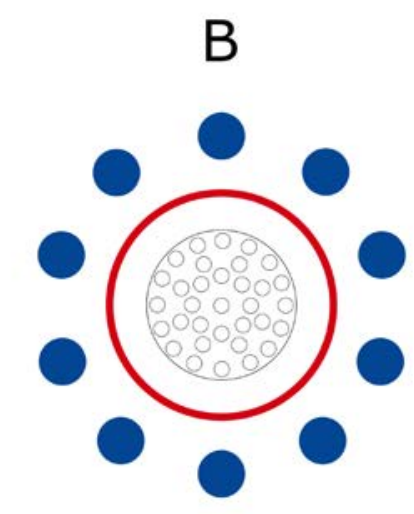

Figure 2: A: Schematic representation of the irradiation container (red circle) with an inserted sample holder between four ${ }^{60}$ Co sources (filled blue circles) in RITA (top view). B: Schematic representation of the irradiation container (red circle) with an inserted sample holder between ten ${ }^{60}$ Co sources (filled blue circles) in BRIGITTE (top view)

\subsection{Dosimeters}

Glassware used for the preparation of the Fricke and ceric-cerous dosimeter solutions and for irradiation was cleaned according to the following protocol adapted from the relevant standard.[43] Two stock solutions of $0.4 \mathrm{~mol} \mathrm{~L}^{-1}$ and $4 \mathrm{~mol} \mathrm{~L}^{-1} \mathrm{H}_{2} \mathrm{SO}_{4}$ (Optima grade, Fisher Scientific UK Limited, Loughborough) in MilliQ water (obtained from a Sartorius Arium pro UV instrument with a built-in UV-digester and Total Organic Carbon (TOC) analyzer; TOC < 5 ppb, specific resistance: $18.2 \mathrm{M} \Omega \mathrm{cm}$ ) were prepared in $1 \mathrm{~L}$ glass volumetric flasks. The prepared $4 \mathrm{~mol} \mathrm{~L}^{-1} \mathrm{H}_{2} \mathrm{SO}_{4}$ stock solution was irradiated in BRIGITTE to 500 Gy absorbed dose in order to eliminate traces of organic contaminants in the water and sulfuric acid, which possibly has an effect on the ferrous ions.[43] Glass ampoules (Kimble, Illinois USA) of $5 \mathrm{~mL}$ volume were rinsed twice with MilliQ water (TOC $<5 \mathrm{ppb}$ ), followed by filling with MilliQ water and boiling for $1 \mathrm{~h}$ on a hot plate. The ampoules were emptied and dried in an oven at $100{ }^{\circ} \mathrm{C}$ until dry, followed by baking in a furnace at $550^{\circ} \mathrm{C}$ for $1 \mathrm{~h}$. The ampoules were filled 
163

with the dosimetry solutions using glass Pasteur pipettes and flame sealed using a propane/oxygen gas mixture.

Due to the extreme sensitivity of the method to trace impurities only new glassware was used for the preparation of the stock solutions and intermediate dilutions. The glassware necessary for the dilutions was cleaned by ultrasound with MilliQ water at $60^{\circ} \mathrm{C}$ for $1 \mathrm{~h}$, followed by rinsing with hot concentrated sulfuric acid. The sulfuric acid was washed thoroughly away with MilliQ water and the glassware was dried in an oven at $100^{\circ} \mathrm{C}$.

The reported errors on the average of the determined dose rates with alanine, Fricke and cericcerous dosimetry are the $99 \%$ confidence intervals as a result of using standard deviations of multiple measurements and t-values corresponding to the relevant degrees of freedom. For Perspex dosimetry, this interval was determined by multiplication of the propagated uncertainty (based on the reported measurement reproducibility and calibration quality by the manufacturer) and a factor of 2.58 to obtain similar $99 \%$ confidence intervals. Confidence intervals were only reported in Table 1, in other cases standard deviations are used to express error bars.

\subsubsection{Alanine dosimetry}

Alanine dosimeters (air-tight sealed plastic foil packages each containing 5 alanine pellets of $5 \mathrm{~mm}$ diameter and $2.5 \mathrm{~mm}$ thickness), were received from NuTec (Hasselt, Belgium), and irradiated in a PMMA grid up to 5, 10, 15, 20 and 25 Gy absorbed dose in the RITA facility at a height of $35 \mathrm{~cm}$, in the center of the irradiation container. The irradiated, unopened packages were returned to NuTec for read-out by Electron Paramagnetic Resonance Spectroscopy (EPR)[51], using a Bruker EMXmicro spectrometer with a 9 inch magnet, equipped with a high-sensitivity resonator ER4119HS-W1, following a protocol described by Anton et al.[5253]

\subsubsection{Fricke dosimetry}

The Fricke dosimeters were prepared and used in accordance with the ISO/ASTM standard 51026:2015 on the Standard Practice for Using the Fricke Dosimetry System.[43] The stock solutions for the dosimeters were prepared by adding $98 \mathrm{mg}$ of $\left(\mathrm{NH}_{4}\right)_{2} \mathrm{Fe}\left(\mathrm{SO}_{4}\right)_{2} \cdot 6 \mathrm{H}_{2} \mathrm{O}$ (99.997 \%, Sigma Aldrich, Overijse, Belgium) and 14.5 mg of NaCl (99.999 \% Sigma Aldrich, Overijse, Belgium), to suppress any effects of possible carbon contaminations, to a $250 \mathrm{~mL}$ volumetric flask. The salts were dissolved in $100 \mathrm{~mL}$ of the $0.4 \mathrm{~mol} \mathrm{~L}^{-1} \mathrm{H}_{2} \mathrm{SO}_{4}$ stock solution. 
194 After dissolution, the volume was adjusted using $0.4 \mathrm{~mol} \mathrm{~L}^{-1} \mathrm{H}_{2} \mathrm{SO}_{4}$. For the calculation of the

195 absorbed doses, temperature corrections were made as described in the ASTM standard.

196 Absorbed doses were calculated using equation (2).

$$
D=\frac{\Delta A}{G_{\text {Tirrad }} \times \varepsilon_{\text {Tmeas }} \times \rho \times d}
$$

197 In this equation $\varepsilon_{25}$ and $G_{25}$ are corrected for measurement and irradiation temperature by 198 equations (3) and (4), with $\varepsilon_{25}=1.61 \times 10^{-6} \mathrm{~mol} \mathrm{~J}^{-1}$ and $G_{25}=1.61 \times 10^{-6} \mathrm{~mol} \mathrm{~J}^{-1}$.

$$
\begin{aligned}
\varepsilon_{\text {Tmeas }} & =\varepsilon_{25}\left[1+0.0069\left(T_{\text {meas }}-25\right)\right] \\
G_{\text {Tirrad }} & =G_{25}\left[1+0.0012\left(T_{\text {irrad }}-25\right)\right]
\end{aligned}
$$

199

200

201

202

203

204

205

206

207

208

209

210

211

212

213

214

215

\subsubsection{Ceric-cerous dosimetry}

Both high and low range ceric-cerous dosimeters (abbreviated as CCH and CCL, respectively) were prepared in accordance with the ISO/ASTM51205:2009 standard.[44] For the preparation of the $\mathrm{Ce}^{4+}$ stock solution, $58.0006 \mathrm{~g}$ of $\mathrm{Ce}\left(\mathrm{SO}_{4}\right)_{2} \cdot 4 \mathrm{H}_{2} \mathrm{O}$ (Optima grade, Fisher Scientific UK Limited, Loughborough) was dissolved in $1 \mathrm{~L}$ stock solution of $0.4 \mathrm{~mol} \mathrm{~L}^{-1} \mathrm{H}_{2} \mathrm{SO}_{4}$. A Ce $\mathrm{Ce}^{3+}$ stock solution was prepared by dissolving $31.0061 \mathrm{~g}$ of $\mathrm{Ce}_{2}\left(\mathrm{SO}_{4}\right)_{3} \cdot 8 \mathrm{H}_{2} \mathrm{O}(99.999 \%$, Sigma Aldrich, Overijse, Belgium) in a total volume of $1 \mathrm{~L}$ MilliQ water. Both stock solutions were allowed to stand at least two weeks in the dark to stabilize in case of the presence of any carbon contaminations. For the preparation of the low range dosimeter solution, $15 \mathrm{~mL}$ of the $\mathrm{Ce}^{3+}$ stock solution, $15 \mathrm{~mL}$ of the $\mathrm{Ce}^{4+}$ stock solution and $48.5 \mathrm{~mL}$ of $4 \mathrm{~mol} \mathrm{~L}^{-1} \mathrm{H}_{2} \mathrm{SO}_{4}$ were combined in a volumetric flask and filled up with MilliQ water up to a total volume of $500 \mathrm{~mL}$. The high range dosimeter solution was prepared by combining $75 \mathrm{~mL}$ of the $\mathrm{Ce}^{3+}$ stock solution, $75 \mathrm{~mL}$ of the $\mathrm{Ce}^{4+}$ stock solution and $42.5 \mathrm{~mL}$ of $4 \mathrm{~mol} \mathrm{~L}^{-1} \mathrm{H}_{2} \mathrm{SO}_{4}$ in a volumetric flask, which was further filled with MilliQ water to a total volume of $500 \mathrm{~mL}$. Both dosimetry solutions were allowed to stand for at least five days in the dark, as recommended.[44] Changes in absorbance $(\triangle A)$, induced by irradiation, are converted into absorbed doses $(D)$ by using equation (5).

$$
D=\frac{f \times \Delta A}{G\left(C e^{3+}\right) \times \varepsilon_{m} \times \rho \times d}
$$

216 In this equation, $f$ is the dilution factor for the irradiated dosimeters, $G\left(\mathrm{Ce}^{3+}\right)$ is calculated as 217 mentioned in the in the ASTM (equation (6)), $\varepsilon_{m}$ is the molar-linear absorption coefficient 
$218\left(561 \mathrm{~m}^{2} \mathrm{~mol}^{-1}\right), \rho$ is the density of the dosimetric solution $\left(1.032 \times 10^{3} \mathrm{~kg} \mathrm{~m}^{-3}\right)$ and $\mathrm{d}$ is the path 219 length of the spectrophotometric cell $(0.010 \mathrm{~m})$.

$$
\begin{aligned}
& G\left(C e^{3+}\right)(\text { low range })=(2.42452-0.0052 \times T) \times 1.036 \times 10^{-7} \\
& G\left(C e^{3+}\right)(\text { high range })=(2.33544-0.0052 \times T) \times 1.036 \times 10^{-7}
\end{aligned}
$$

220

221

222

223

224

225

226

227

228

229

230

231

232

233

234

235

236

237

238

239

240

241

242

243

244

\subsubsection{Perspex (PMMA) dosimetry}

The dose calibration of the irradiation chambers was performed using either Harwell's Red Perspex dosimeters (Type 4034, $\lambda=640 \mathrm{~nm}$ ) or Amber Perspex dosimeters (Type 3042, $\lambda=$ $603 \mathrm{~nm}$ or $651 \mathrm{~nm}$ ) (Harwell Dosimetrics, Oxfordshire, UK). The $3 \mathrm{~mm}$ thick slits were placed in a UV-VIS cell holder (Hellma Analytics BVBA, Kruibeke, Belgium) to ensure a reproducible positioning and perpendicular alignment with respect to the light beam. The absorbance of the dosimeters belonging to a given batch was converted to absorbed dose using the calibration curve determined by Harwell. Harwell's calibration is traceable to the UK standard of absorbed dose at the National Physical Laboratory. For Amber Perspex the relative standard deviation of specific absorbance measurements on sets of dosimeters is $2.5 \%$ and for Red Perspex, it is $2 \%$.

\subsection{UV-VIS spectrometry}

The working principle of the Fricke, ceric-cerous and Perspex dosimeters is based on the change in absorption of the dosimeter material under the effect of absorbed gamma radiation.

The UV-VIS measurements were performed using a Shimadzu UV-1800 spectrophotometer with a spectral bandwidth of $1 \mathrm{~nm}$. The spectrophotometer performance was verified after baseline correction by the use of certified reference materials obtained from Hellma Analytics BVBA, following the relevant ASTM standard.[54] The accuracy of the wavelength scale in both the ultraviolet and visible region of the electromagnetic spectrum was verified against a holmium oxide glass filter 666-F1 and a holmium perchlorate liquid filter 667-UV-5 certified reference (Hellma Analytics, certified by Deutsche Akkreditierungsstelle GmbH). The absorbance scale accuracy of the instrument in the visible region was verified to be within the $95 \%$ confidence intervals reported on the certificate with the use of F2, F3 and F4 neutral density glass filters (Hellma Analytics, all certified by Deutsche Akkreditierungsstelle GmbH) at $440.0 \mathrm{~nm}, 465.0 \mathrm{~nm}, 546.1 \mathrm{~nm}, 546.1 \mathrm{~nm}, 590.0 \mathrm{~nm}$ and $635.0 \mathrm{~nm}$. The absorbance accuracy of the spectrophotometer in the UV-region was verified by the use of liquid reference materials 667 UV-20, 667 UV-60, and UV-600 against UV-14 in the reference cell (Hellma Analytics, certified by Deutsche Akkreditierungsstelle GmbH). 
The read-out wavelength for Fricke dosimetry was 303 nm, ceric-cerous dosimeters were readout at $320 \mathrm{~nm}$. Red Perspex dosimeters' absorbances were determined at $640 \mathrm{~nm}$ and Amber Perspex dosimeters at $603 \mathrm{~nm}$. For all liquids, cuvettes with a path length of $10 \mathrm{~mm}$ were used.

251

252

253

\subsection{Irradiation of dosimeters}

All dosimeters were irradiated in RITA and/or BRIGITTE. The Amber variant of Perspex dosimeters was loaded in RITA, whereas in BRIGITTE only ceric-cerous and Red Perspex dosimeters were irradiated. An overview of the employed dosimeters, delivered doses and irradiation facilities is shown in Figure 3. Also, the dose range per dosimeter is indicated in this schematic.

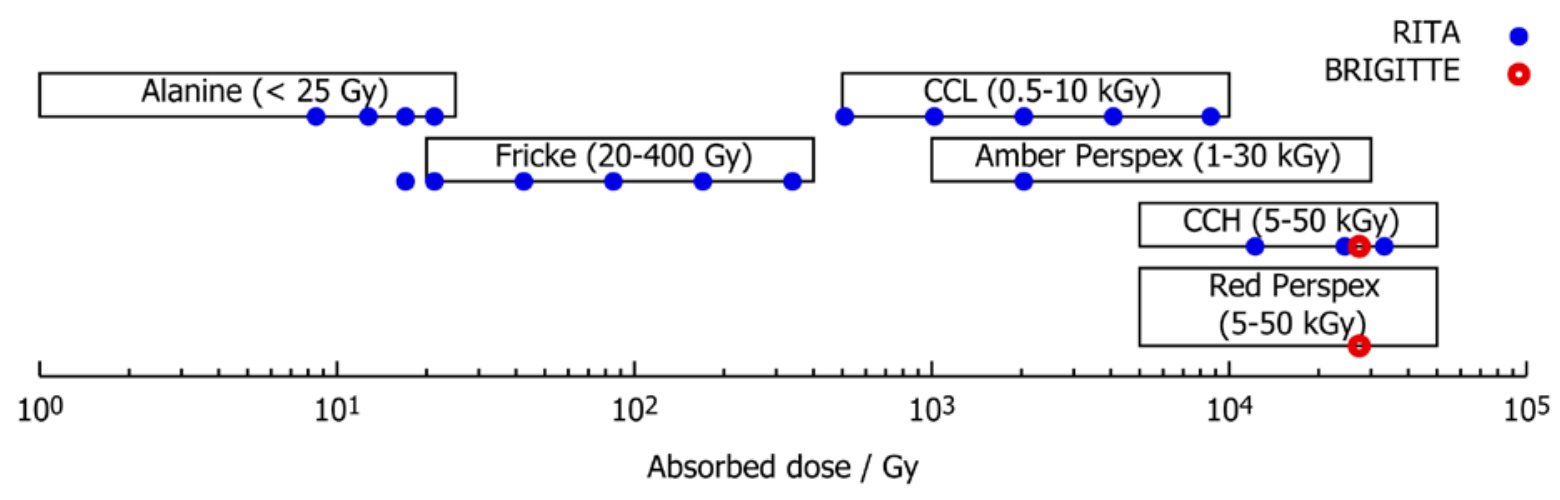

Figure 3: Schematic of the working ranges of all applied dosimeters, with delivered doses by RITA (blue closed dots) and by BRIGITTE (red open dots). Low range ceric-cerous dosimeters and high range ceric-cerous dosimeters are abbreviated as CCL and CCH.

For the irradiation of dosimeters and samples, in-house manufactured poly(methyl methacrylate) (PMMA) sample holders were used, similar to the one shown in Figure 4. The choice of the material of the sample holder (PMMA) was made in order to establish secondary charged particle equilibrium in the sample positions since the thickness of PMMA is more than $3 \mathrm{~mm} .[55]$ All positions are numbered for dose rate mapping. The high dose rate gamma field of BRIGITTE was characterized by placing the same PMMA sample holder as used in RITA with its central position aligned to the central axis of the cylinder-shaped irradiation container, at $110 \mathrm{~cm}$ distance from the lid of the container.

Experiments with an aluminum sample holder and epoxy resin cups (thickness $=3.77 \mathrm{~mm}$ ) were conducted with Red Perspex dosimeters in BRIGITTE. The metal parts were put together as shown in Figure 4. This holder has a diameter of $160 \mathrm{~mm}$ and is $35 \mathrm{~mm}$ high, holes for positioning samples have a diameter of $16 \mathrm{~mm}$. The aluminum holder will ensure stable placement of the samples, even if the polymer degrades due to the high absorbed dose, and 


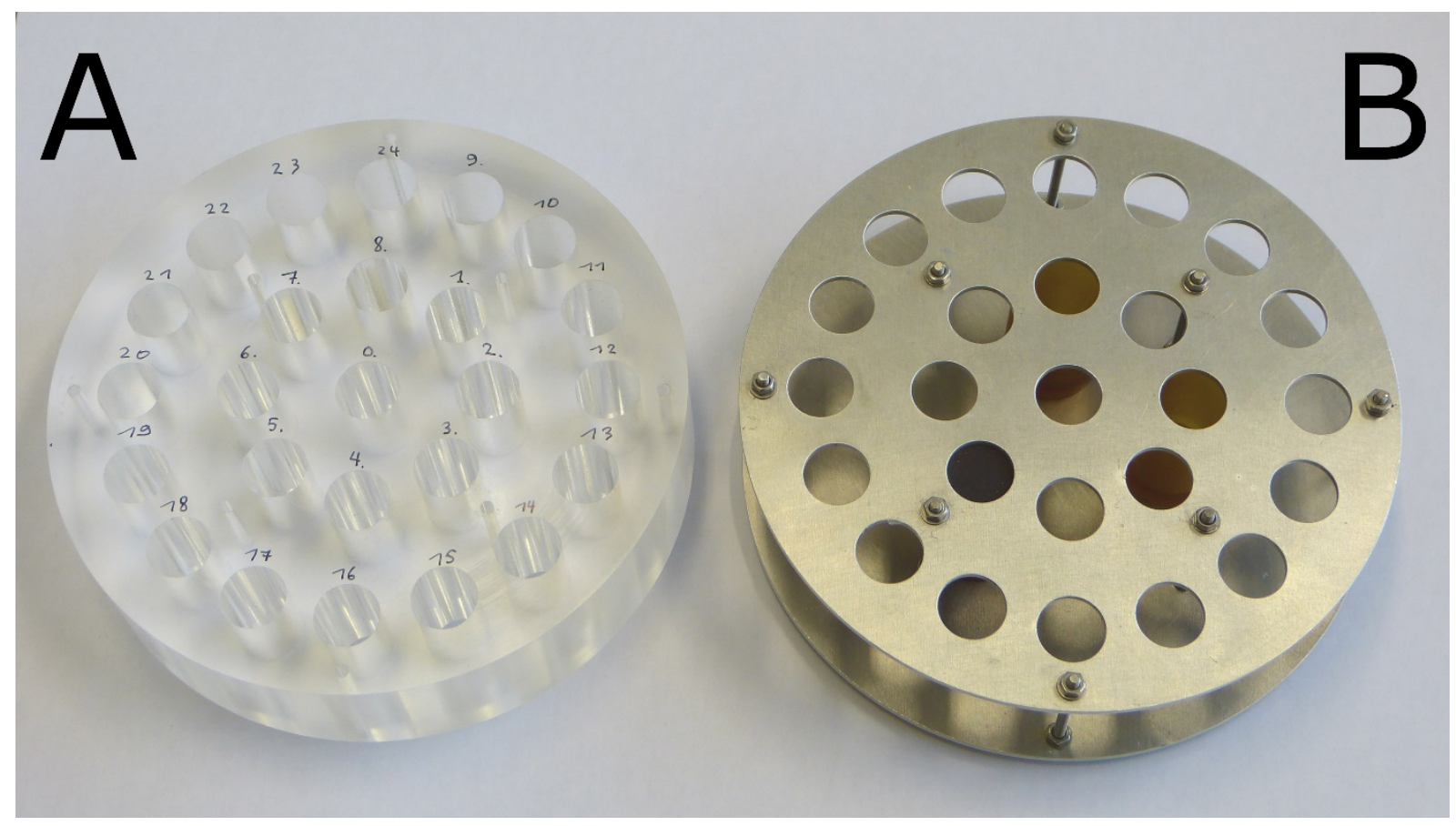

Figure 4: PMMA sample holder (A) and aluminum sample holder in which epoxy cups are inserted (B) for gamma irradiations in BRIGITTE.

\section{$279 \quad 2.5$ Radiolysis study of TODGA}

280 A solution of $0.05 \mathrm{~mol} \mathrm{~L}^{-1}$ TODGA (Technocomm Ltd., Wellbrae United Kingdom) in $n$ dodecane (Lot 16C020503, VWR) was prepared; $0.5 \mathrm{~mL}$ fractions were transferred to $1.5 \mathrm{~mL}$ glass vials for irradiation. To half of the samples, equal volumes of $2.5 \mathrm{~mol} \mathrm{~L}^{-1}$ trace metal grade $\mathrm{HNO}_{3}$ solution (Fisher Scientific, Merelbeke, Belgium) were added.

Gamma irradiations were conducted in BRIGITTE in the PMMA sample holder which was used for dosimetry. The absorbed doses were 100, 200, 300 and 400 kGy, based on dosimetry using the Red Perspex dosimeters. A sample for aging control was used as the reference.

Quantitative HPLC-ESI-MS/MS was performed with a Qtrap6500 instrument (ABSciex, Darmstadt, Germany) coupled by electrospray ionization with an Agilent 1260 HPLC. The used column was of the type Phenyl-X $(100 \times 4.6 \mathrm{~mm}$; $2.6 \mu \mathrm{m})$ (Thermo Fisher). Elution was obtained with a gradient of $\mathrm{H}_{2} \mathrm{O}$ with $0.1 \%$ formic acid and acetonitrile with $0.1 \%$ formic acid, at a flow rate of $0.7 \mathrm{~mL} \mathrm{~min}^{-1}$. The temperature of the column oven was set at $40^{\circ} \mathrm{C}$. Quantification after HPLC separation was performed using ESI-MS/MS detection in the $340.2 \mathrm{~m} / \mathrm{z}$ as the product ions. 


\section{Results and discussion}

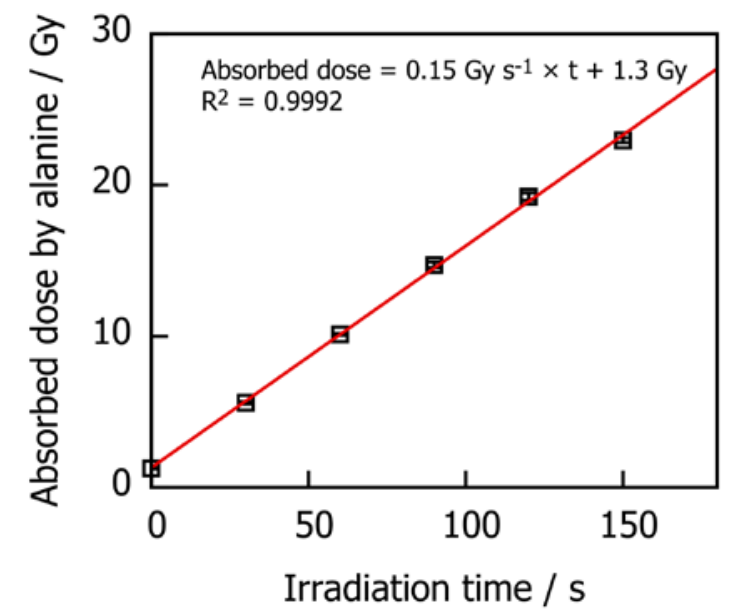

\subsection{Irradiation of dosimeters in RITA} out values of the dosimeters in RITA.

\subsubsection{Alanine dosimeters} is linear to the irradiation time. calibration transfer dosimeter.

The actual absorbed dose rate in the center position in the irradiation cavity of RITA was determined using different dosimetric methods. Samples and dosimeters were at the maximum dose rate and in the axially homogeneous part of the irradiation field. In the span [-25 mm, +25 $\mathrm{mm}$ ], the dose rate variation is less than $2 \%$. The height of both the samples and dosimeters (approx. $30 \mathrm{~mm}$ ) was well within this homogeneous zone The value of the 'transient dose', i.e. the absorbed dose which the samples receive during positioning, loading and unloading, was obtained from alanine dosimetry. The transient dose is used to make a correction on the read-

The results of the consecutive dosimetry in the central position in RITA using alanine dosimeters with increasing irradiation times are shown in Figure 5 . The transient dose, with $0 \mathrm{~s}$ residence time) was $1.26 \pm 0.02 \mathrm{~Gy}$. This agrees with the y-axis intercept (1.3 $\pm 0.2 \mathrm{~Gy})$ of the linear fitting of the response as a function of the irradiation time. The value of 0.9992 for $\mathrm{R}^{2}$ of the linear least square fitting, indicates that the dependency of the read-out of the absorbed dose

The average dose rate calculated from the five consecutively irradiated, transient dose corrected, packages of 5 alanine pellets is $530 \pm 18 \mathrm{~Gy} \mathrm{~h}^{-1}$. The determined dose rates as a function of irradiation time are shown in Figure 6. Alanine dosimetry was conducted to obtain an independent (read-out externally) traceable dose calibration with a Type I dosimeter as a 


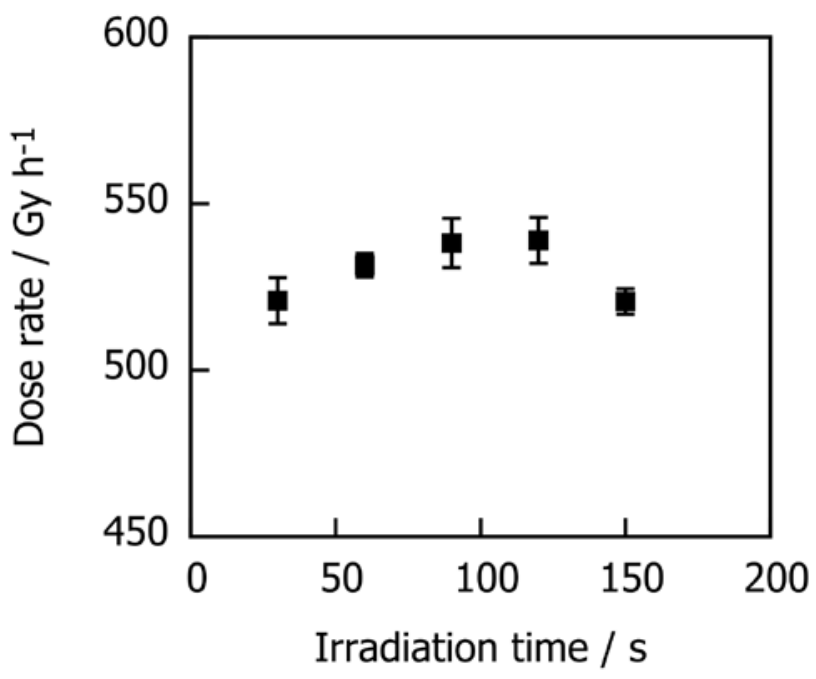

Figure 6: Dose rate in RITA determined with alanine/EPR dosimetry. The error bars represent standard deviations of the 5 repetitions in every dosimeter package.

325

326

327

\subsubsection{Fricke dosimeters}

The Fricke dosimeters were used to confirm the dose rate values obtained from the alanine dosimeters. Fricke dosimeters are liquid type I dosimeters, which are prepared in sample-sized ampoules (as described in 2.2.2). In Figure 7, the calibration curve of the Fricke dosimeters in RITA is shown. The change in absorbance can be fitted to a second order polynomial function of the absorbed dose as shown in equation (7).[43]

$$
\Delta A=b_{0}+b_{1} \times D+b_{2} \times D^{2}
$$

In this equation is $\Delta \mathrm{A}$ the change in absorbance, $\mathrm{D}$ the absorbed dose and $b_{0}, b_{1}$ and $b_{2}$ are the coefficients of the second order polynomial fit. The value of coefficient $b_{1}$ equals $(4.0 \pm 0.3) \times 10^{-3}$, when $b_{0}$ is considered to be zero $b_{1}$ equals $(3.5 \pm 0.1) \times 10^{-3}\left(\mathrm{R}^{2}=0.9999\right)$. The latter assumption is legitimated by the fact that no change in absorbance is assumed if the dosimeters are not irradiated, the $\mathrm{R}^{2}$ of 0.9999 confirms this. This result of $b_{1}$ is comparable to the value reported in the ASTM for Fricke dosimetry[43] of $3.6 \times 10^{-3}$, confirming a good match between the dose rate determined with Fricke dosimeters and the alanine/EPR methods. The coefficient for the second order part of the equation is relatively small, which means that the curve is very close to being linear. The reason for this term, is that towards the end of Fricke's application range this second order part can become more significant. 
341 In Figure 8 the determined dose rate is shown as a function of the irradiation time, all the 342 absorbed doses were in the working range of the Fricke dosimeters. The average determined dose rate is $530 \pm 27 \mathrm{~Gy} \mathrm{~h}^{-1}$.

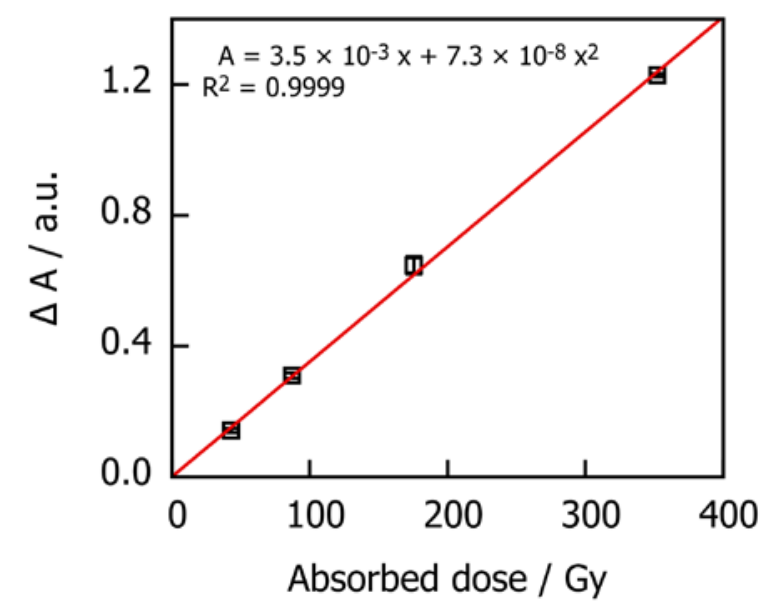

Figure 7: Calibration curve of Fricke dosimeters in RITA, error bars represent the standard deviation of three repeated measurements. The change in measured absorbance is visualized as function of the absorbed dose, determined by alanine dosimetry.

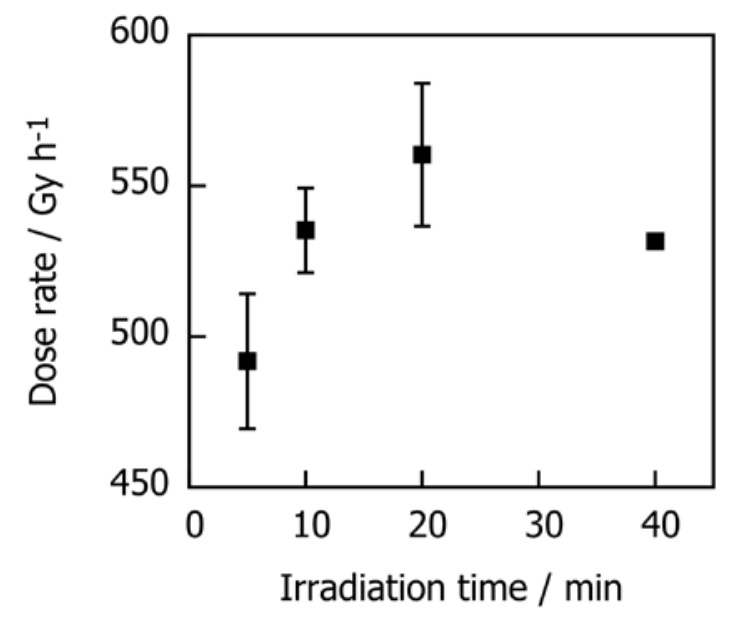

Figure 8: Dose rate in RITA determined with Fricke dosimetry using the literature values for Fricke dosimetry. Every data point is based on three repetitions, standard deviations on these repetitions are visualized by the error bars.

\subsubsection{Ceric-cerous dosimetry}

352 Determined dose rates for different irradiation times with low range ceric-cerous dosimeters

353 are shown in Figure 9. The average determined dose rate was $513 \pm 17 \mathrm{~Gy} \mathrm{~h}^{-1}$. High range 354 ceric-cerous dosimeters were also irradiated for three different durations. The average dose rate 355 at this central position of the cavity was $546 \pm 14 \mathrm{~Gy} \mathrm{~h}^{-1}$. 


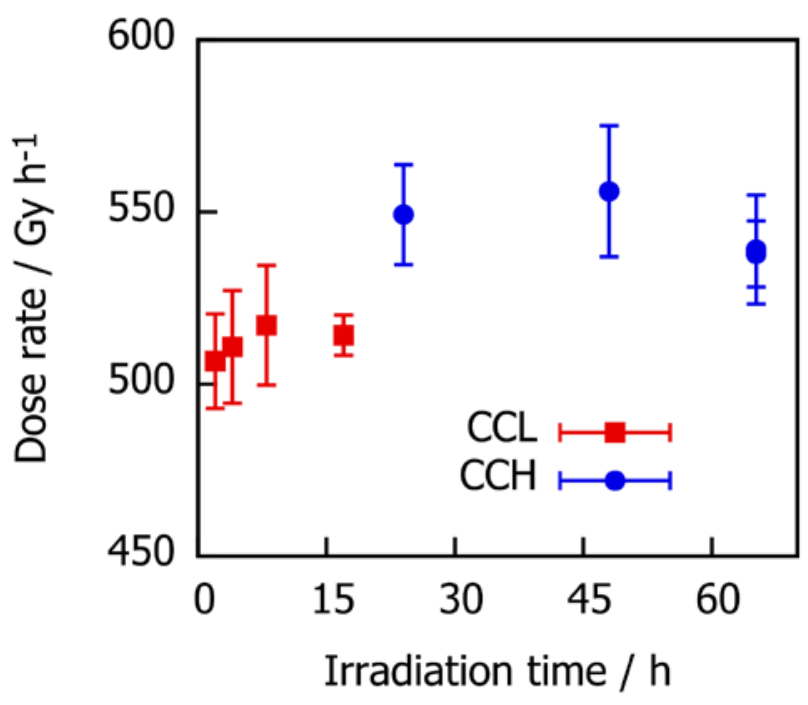

Figure 9: Dose rate determined with CCL (red squares) and CCH (blue dots). Every irradiation was repeated three times, of which the standard deviation was calculated and visualized by error bars.

\subsubsection{Perspex dosimeters}

360 The Perspex dosimeters (Amber and Red) are routine dosimeters of Type II classification under 361 the ISO/ASTM standard on the practice for dosimetry in radiation processing.[41] Their ease 362 of use (in comparison to ceric-cerous dosimeters) make them a very practical tool to perform routine dosimetry and particularly for dose rate mapping.[56] The determined dose rate based on the specific absorbance of the irradiated Amber Perspex dosimeters at the center of the sample holder was $510 \pm 33 \mathrm{~Gy} \mathrm{~h}^{-1}$. This was derived from the calibration curve provided by the supplier of the dosimeters. By using Amber Perspex dosimeters in RITA and using Red Perspex dosimeters in BRIGITTE, the irradiation time $(2 \mathrm{~h})$ is kept identical because of their difference in application range, thus eliminating possible effects caused by positioning.

\subsubsection{Overview of dosimetry in RITA}

Table 1 lists the dose rate values determined with all the dosimetry methods used in this study. The shown errors are the $99 \%$ confidence intervals, as a result of the repeated measurements.

372 None of the reported values are significantly different. The dose rates determined with CCL 373 and Amber Perspex seem a bit low and $\mathrm{CCH}$ a bit high compared to Fricke and alanine 374 dosimetry, although confidence intervals still overlap in these cases. This is crucial information, 375 since alanine and Fricke dosimeters are not practically usable in the high dose rate field of 376 BRIGITTE (approx. $13.6 \mathrm{kGy} \mathrm{h}^{-1}$ ). The alanine and Fricke dosimeters would be saturated within less than a few minutes, and the dose they receive during emplacement of the irradiation canister would become very significant. For further experiments concerning dose rate mapping in a higher irradiation field, both ceric-cerous high range and Red Perspex dosimeters are used. 
Table 1: Comparison of dose rate in RITA at $35 \mathrm{~cm}$ height, central position determined with the various dosimeter systems.

\begin{tabular}{ccc} 
Method & Determined dose rate $\left.\mathbf{( G y} \mathbf{~ h}^{\mathbf{- 1}}\right)$ & Reference \\
\hline Alanine & $530 \pm 18$ & ISO/ASTM 51607[57] \\
Fricke & $530 \pm 27$ & ISO/ASTM 51026[43] \\
Ceric-cerous low range & $513 \pm 17$ & ASTM 51205[44] \\
Ceric-cerous high range & $546 \pm 14$ & ASTM 51205[44] \\
Amber Perspex & $510 \pm 33$ & ISO 51276[56] \\
\hline
\end{tabular}

\subsection{Irradiation of dosimeters in BRIGITTE}

\subsubsection{Influence of the sample holder}

One of the reasons to use the previously mentioned PMMA block, is reproducible positioning of samples. However, since polymers degrade under gamma irradiation and finally lose all structural integrity as the absorbed dose accumulates, using a metal sample holder would be a great improvement for gamma irradiations in a high dose rate gamma irradiation facility such as BRIGITTE. For this purpose, an aluminum holder was designed.

While this seems like the perfect solution, dosimeters are not properly surrounded to ensure a charged particle equilibrium. For this reason, a separate experiment was set-up, in which the determined dose rate with and without a polymer (epoxy resin) shielding were compared. The thickness of the epoxy cups, of $3.77 \mathrm{~mm}$, should ensure a charged particle equilibrium,[55] without causing large shielding effect.

The data shown in Figure 10, indicate there is no significant difference between irradiation of Red Perspex dosimeters in the epoxy resin containers and the plain dosimeters in the aluminum holder for the two positions. Reproducible dosimetry with Perspex dosimeters is possible, even without using a polymer surrounding. For the two control positions (were the direct environment of the dosimeter was not changed), there was also no significant difference observed; control 1: $8.70 \pm 0.17 \mathrm{kGy} \mathrm{h}^{-1}$ and $8.70 \pm 0.17 \mathrm{kGy} \mathrm{h}^{-1}$, control 2: $7.55 \pm 0.15 \mathrm{kGy} \mathrm{h}^{-}$ ${ }^{1}$ and $7.45 \pm 0.15 \mathrm{kGy} \mathrm{h}^{-1}$.

For future experiments, the aluminum sample holder can thus be used with no need to insert a PMMA block for conducting dosimetry and following irradiations. This is important, since in high irradiation fields, such as BRIGITTE, these kind of blocks are destroyed during irradiations over a few MGy, which was observed in practice. 


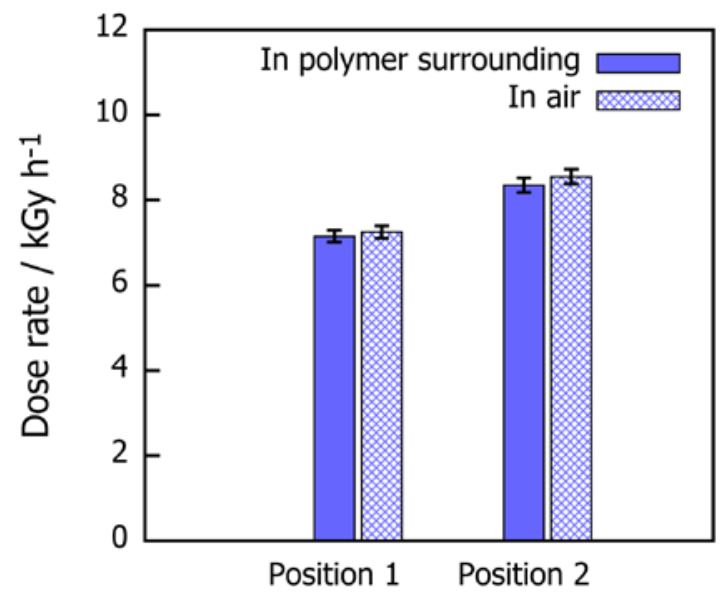

Figure 10: Determined dose rates with Red Perspex dosimetry in the aluminum sample holder with (solid fill) and without 407 (checkered fill) epoxy resin shielding.

\section{$408 \quad$ 3.2.2 Dose rate mapping}

409 The BRIGITTE irradiation facility uses activated control rods of the BR2 reactor, installed 410 centro-symmetrically around the BRIGITTE container. The use of a uniform dose rate 411 throughout a series of samples is necessary to exclude effects related to differences in dose 412 rates. An analysis of the dose rate distribution in space was performed by using $\mathrm{CCH}$ and Red 413 Perspex dosimeters placed in the central axis of the cylinder-shaped irradiation cavity and at 414 the perimeter of a $10 \mathrm{~cm}$ diameter circle. The result of this dose rate mapping is visualized in 415 Figure 11, error bars for Red Perspex are $2 \%$, as this is the coefficient of variation reported by 416 the manufacturer. For the high range ceric-cerous dosimeters standard deviations of three 417 repetitions are shown.

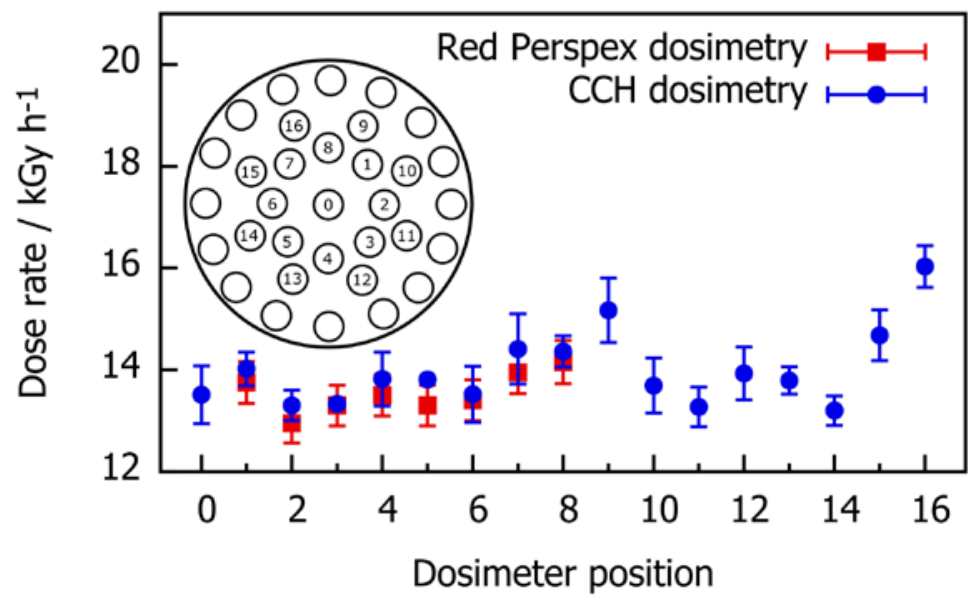


421 The sample-size matched dose rate mapping for the samples was performed by the use of high 422 range ceric-cerous dosimeters in the PMMA sample holder block. The delivered dose to the 423 solvent extraction samples was calculated by multiplication of the irradiation time with the 424 average dose rate (determined with $\mathrm{CCH}$ ) in the most homogeneous part of the irradiation field.

425 As the dose rate mapping revealed, for three positions the dose rate was higher than the average 426 by $12 \%, 9 \%$ and $19 \%$ respectively (positions 9,15 and 16). This azimuthal inhomogeneity is 427 caused by differences in activity of the ${ }^{60} \mathrm{Co}$ sources. Therefore, these positions were not used 428 for the irradiation of TODGA samples. By restricting the use to only 14 positions, the applied 429 dose rate varied with less than $7 \%$ compared to the central position of the sample holder. The 430 outer positions were omitted since they are closer to the ${ }^{60} \mathrm{Co}$ gamma sources. Consequentially, 431 the non-uniformity in the dose rate field will be amplified for these positions, which is 432 unfavorable for dosimetric studies. Differences in dose rates applied to samples are minimized 433 by limiting the sample positions to the center, excluding an additional parameter which possibly 434 influences the behavior of certain radiolysis processes. This influence has been reported during 435 the irradiation of solvent extraction systems,[58] gold solutions[59] and methyl orange 436 solutions.[60] The average dose rate in this part of the field is $13.6 \pm 0.5 \mathrm{kGy} \mathrm{h}^{-1}$, this is the 437 value which was used to calculate the absorbed dose of the irradiated TODGA samples in the 438 next section. Differences in activity of the ${ }^{60}$ Co sources cause azimuthal inhomogeneities of the 439 irradiation field in the cavity. In case all sources have an identical activity, the dose rate 440 distribution would be symmetric as seen in Gammacell 220 irradiator devices.[61]

\subsection{Gamma irradiation of TODGA}

442 The ligand concentration as a function of the absorbed dose is plotted in Figure 12. Data shown 443 in red refers to TODGA in $n$-dodecane, whereas data in blue refers to TODGA in contact with $4442.5 \mathrm{~mol} \mathrm{~L}^{-1} \mathrm{HNO}_{3}$. Dotted lines are literature values[15] for both TODGA in $n$-dodecane (red) 445 and TODGA in contact $2.5 \mathrm{~mol} \mathrm{~L}^{-1} \mathrm{HNO}_{3}$ (blue). Dose constants (d) are calculated from the 446 linear fit of the natural logarithm of the ligand concentration as a function of the absorbed dose. 447 The irradiations were conducted in the same absorbed dose range with a similar dose rate and 448 identical gamma energies as mentioned in the literature.[15] 


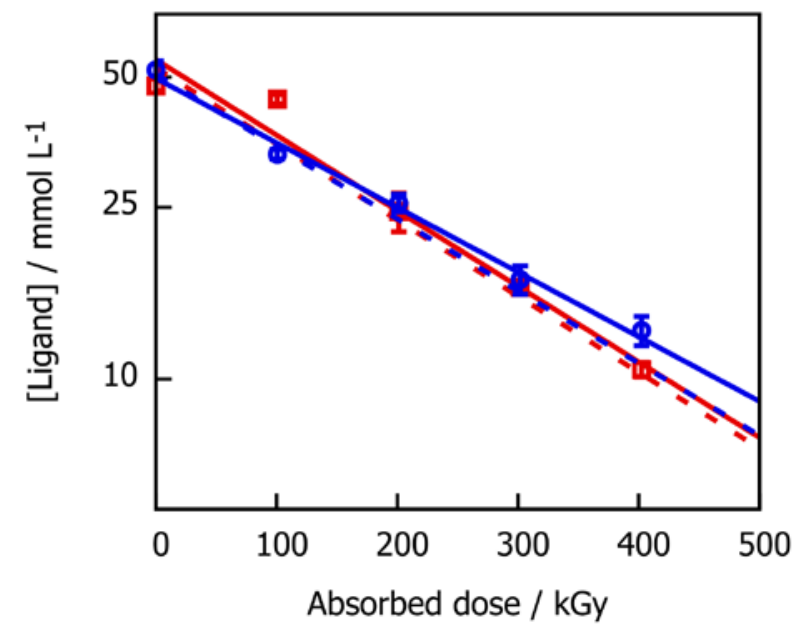

Figure 12: Influence of the absorbed dose on the concentration of TODGA in n-dodecane ( $\square$ ), and for TODGA in ndodecane in contact with $2.5 \mathrm{~mol} \mathrm{~L}^{-1} \mathrm{HNO}_{3}(\mathrm{O})$ with their respective fittings (一) and (一). Dose constants found by Zarzana et al.[15] for TODGA in n-dodecane, and TODGA in n-dodecane in contact with $2.5 \mathrm{~mol} \mathrm{~L}^{-1} \mathrm{HNO}_{3}$ are displayed with dotted lines (- - ) and (- - ).

454 The determined dose constant for TODGA in $n$-dodecane is $(4.0 \pm 0.4) \times 10^{-6}$ Gy, which is 455 within experimental uncertainty identical to the value reported by Zarzana et al.: $(4.1 \pm 0.3) \times$ $45610^{-6} \mathrm{~Gy}$.[15] Also the value for TODGA in $\mathrm{HNO}_{3},(3.4 \pm 0.2) \times 10^{-6} \mathrm{~Gy}$, is very similar to the 457 literature value of $(3.8 \pm 0.3) \times 10^{-6} \mathrm{~Gy}$.[15] It should be noted that these values from Zarzana 458 et al. were determined after irradiation with a (dry) ${ }^{60} \mathrm{Co}$ Gamma Cell source (Nordion, Ottawa, 459 Canada).[15] Also dose constants published by Sugo et al.[17] are similar (4.5 × 10-6 Gy) for 460 an initial concentration of $0.05 \mathrm{~mol} \mathrm{~L}^{-1}$ TODGA in $n$-dodecane, in absence of an aqueous phase. 461 These results confirm the reproducibility of the whole chain from sample preparation over 462 dosimetry to analysis. 
464

465

466

467

468

469

470

471

472

473

474

475

476

477

478

479

480

481

482

483

484

485

486

\section{Conclusions}

In this study it is shown that the dose rate constants for TODGA obtained with dry ${ }^{60} \mathrm{Co}$ irradiation facilities can be reproduced in a pool-type irradiation facility with a more complex geometry. This is achieved by reproducible sample positioning, validation of dosimetry and accurate dose rate mapping of the irradiation chamber. It can be concluded that the performance of Amber Perspex dosimeters is not significantly different from ceric-cerous (high and low range), Fricke and alanine dosimeters. The latter are type I dosimeters, which are dosimeters of high metrological quality and for which independent correction factors can be used to express individual influence quantities in a well-defined way.[41] The results were first confirmed by irradiations in RITA, the low dose rate facility of approx. $0.5 \mathrm{kGy} \mathrm{h}^{-1}$. Additionally, irradiation of high-range ceric-cerous and Red Perspex dosimeters in BRIGITTE (the high dose rate facility, approx. $13.6 \mathrm{kGy} \mathrm{h}^{-1}$ ) led to similar results. In future experiments, Red Perspex dosimetry can be a valid alternative for dosimetry and dose rate mapping of the irradiation cavity prior to irradiation experiments. Dose rate mapping proved to be crucial for evaluation of the irradiation field and is therefore strongly advised to be performed whenever the configuration of the sources is changed or samples are arranged differently. The main advantages of using Perspex dosimeters for this purpose are: (1) it does not require any manipulation of chemicals, (2) has a robust read-out method and (3) is applicable to the high dose rate field of BRIGITTE. Moreover, it is shown that future irradiations could also be conducted in an aluminum sample holder, without using a PMMA body (which degrades quickly under high gamma irradiation), since there was no significant effect of the presence of the polymer on Red Perspex dosimeters observed. Our findings open perspectives to future radiolysis research using flexible, high dose rate pool-type gamma irradiation facilities. 


\section{Acknowledgements}

488 The author would like to thank the NEO unit at SCK CEN for making the irradiation 489 experiments possible. B.V. acknowledges the SCK CEN Academy for providing funding for a $490 \quad \mathrm{PhD}$ fellowship. Analyses of the irradiated samples was conducted at Forschungszentrum Jülich $491 \mathrm{GmbH}$ (Germany) at ZEA-3 by Michelle Hupert with support of Andreas Wilden (IEK-6). The 492 author would also like to thank the people of the Laboratory for Nuclear Calibrations (LNK) of 493 SCK CEN. 
1. Taylor, R.: Reprocessing and Recycling of Spent Nuclear Fuel. Woodhead Publishing United Kindom, 2015; p 684.

2. Lanham, W. B.; Runion, T. C.; PUREX Process for Plutonium and Uranium Recovery; Oak Ridge National Laboratory: United States, 1949.

3. Madic, C.; Boullis, B.; Baron, P.; Testard, F.; Hudson, M. J.; Liljenzin, J. O.; Christiansen, B.; Ferrando, M.; Facchini, A.; Geist, A.; Modolo, G.; Espartero, A. G.; De Mendoza, J.: Futuristic back-end of the nuclear fuel cycle with the partitioning of minor actinides. J. Alloys Compd. 444-445, 23 (2007). 4. Modolo, G.; Geist, A.; Miguirditchian, M.: Minor actinide separations in the reprocessing of spent nuclear fuels. In Reprocessing and Recycling of Spent Nuclear Fuel, Taylor, R., Ed. Woodhead Publishing United Kingdom, 2015; pp 245-287.

5. Sasaki, Y.; Sugo, Y.; Suzuki, S.; Tachimori, S.: The novel extractants, diglycolamides, for the extraction of lanthanides and actinides in $\mathrm{HNO}_{3}$-n-dodecane system. Solvent Extr. Ion Exch. 19, 91 (2001).

6. Ansari, S. A.; Pathak, P.; Mohapatra, P. K.; Manchanda, V. K.: Chemistry of diglycolamides: promising extractants for actinide partitioning. Chem. Rev. 112, 1751 (2012).

7. Mezyk, S. P.; Horne, G. P.; Mincher, B. J.; Zalupski, P. R.; Cook, A. R.; Wishart, J. F.: The Chemistry of Separations Ligand Degradation by Organic Radical Cations. Procedia Chem. 21, 61 (2016). 8. Mezyk, S. P.; Mincher, B. J.; Dhiman, S. B.; Layne, B.; Wishart, J. F.: The role of organic solvent radical cations in separations ligand degradation. J. Radioanal. Nucl. Chem. 307, 2445 (2015).

9. Mincher, B. J.; Curry, R. D.: Considerations for choice of a kinetic fig. of merit in process radiation chemistry for waste treatment. Appl. Radiat. Isot. 52, 189 (2000).

10. Getoff, N.; Radiation chemistry and the environment; International Atomic Energy Agency: 1998; pp 121-131.

11. Mincher, B. J.; Arbon, R. E.; Knighton, W. B.; Meikrantz, D. H.: Gamma-ray-induced Degradation of PCBs in Neutral Isopropanol Using Spent Reactor Fuel. Appl. Radiat. Isot. 45, 879 (1994).

12. Ansari, S. A.; Pathak, P. N.; Manchanda, V. K.; Husain, M.; Prasad, A. K.; Parmar, V. S.: $N, N, N^{\prime}, N^{\prime}-$ Tetraoctyl Diglycolamide (TODGA): A Promising Extractant for Actinide-Partitioning from High-Level Waste (HLW). Solvent Extr. Ion Exch. 23, 463 (2005).

13. Sasaki, Y.; Rapold, P.; Arisaka, M.; Hirata, M.; Kimura, T.; Hill, C.; Cote, G.: An Additional Insight into the Correlation between the Distribution Ratios and the Aqueous Acidity of the TODGA System. Solvent Extr. Ion Exch. 25, 187 (2007).

14. Sasaki, Y.; Tsubata, Y.; Kitatsuji, Y.; Sugo, Y.; Shirasu, N.; Morita, Y.; Kimura, T.: Extraction behavior of metal ions by TODGA, DOODA, MIDOA and NTAamide extractants from $\mathrm{HNO}_{3}$ to $n$ dodecane. Solvent Extr. Ion Exch. 31, 401 (2013).

15. Zarzana, C. A.; Groenewold, G. S.; Mincher, B. J.; Mezyk, S. P.; Wilden, A.; Schmidt, H.; Modolo, G.; Wishart, J. F.; Cook, A. R.: A Comparison of the $\gamma$-Radiolysis of TODGA and T(EH)DGA Using UHPLCESI-MS Analysis. Solvent Extr. Ion Exch. 33, 431 (2015).

16. Galán, H.; Núñez, A.; Espartero, A. G.; Sedano, R.; Durana, A.; de Mendoza, J.: Radiolytic Stability of TODGA: Characterization of Degraded Samples under Different Experimental Conditions. Procedia Chem. 7, 195 (2012).

17. Sugo, Y.; Izumi, Y.; Yoshida, Y.; Nishijima, S.; Sasaki, Y.; Kimura, T.; Sekine, T.; Kudo, H.: Influence of diluent on radiolysis of amides in organic solution. Radiat. Phys. Chem. 76, 794 (2007).

18. Sugo, Y.; Sasaki, Y.; Tachimori, S.: Studies on hydrolysis and radiolysis of $N, N, N^{\prime}, N^{\prime}$-tetraoctyl3-oxapentane-1,5-diamide. Radiochim. Acta 90, 161 (2002).

19. Galán, H.; Zarzana, C. A.; Wilden, A.; Nunez, A.; Schmidt, H.; Egberink, R. J.; Leoncini, A.; Cobos, J.; Verboom, W.; Modolo, G.; Groenewold, G. S.; Mincher, B. J.: Gamma-radiolytic stability of new methylated TODGA derivatives for minor actinide recycling. Dalton Trans. 44, 18049 (2015). 

M. E.; Hupert, M.; Stark, A.; Modolo, G.: Radiolytic and hydrolytic degradation of the hydrophilic diglycolamides. Solvent Extr. Ion Exch. 36, 347 (2018).

21. Modolo, G.; Odoj, R.: Influence of the purity and irradiation stability of Cyanex 301 on the separation of trivalent actinides from lanthanides by solvent extraction. J. Radioanal. Nucl. Chem. 228, 54883 (1998).

549 22. Modolo, G.; Seekamp, S.: Hydrolysis and Radiation Stability of the ALINA Solvent for 550 Actinide(III)/Lanthanide(III) Separation during the Partitioning of Minor Actinides. Solvent Extr. Ion 551 Exch. 20, 195 (2002). 23. Schmidt, H.; Wilden, A.; Modolo, G.; Bosbach, D.; Santiago-Schübel, B.; Hupert, M.; Švehla, J.; Grüner, B.; Ekberg, C.: Gamma Radiolysis of the Highly Selective Ligands CyMe ${ }_{4} B T B P$ and $\mathrm{CyMe}_{4} \mathrm{BTPhen:}$ Qualitative and Quantitative Investigation of Radiolysis Products. Procedia Chem. 21, 32 (2016).

24. Horne, G. P.; Mezyk, S. P.; Mincher, B. J.; Zarzana, C. A.; Rae, C.; Tillotson, R. D.; Schmitt, N. C.; Ball, R. D.; Ceder, J.; Charbonnel, M.-C.; Guilbaud, P.; Saint-Louis, G.; Berthon, L.: DEHBA (di-2ethylhexylbutyramide) gamma radiolysis under spent nuclear fuel solvent extraction process conditions. Radiat. Phys. Chem., 108608 (2019).

25. Aneheim, E.; Bauhn, L.; Ekberg, C.; Foreman, M.; Löfström-Engdahl, E.: Extraction experiments after radiolysis of a proposed GANEX solvent - the effect of time. Procedia Chem. 7, 123 (2012).

26. Malo, M.; Garcia-Cortes, I.; Munoz, P.; Morono, A.; Hodgson, E. R.: A dedicated system for in situ testing of gamma ray induced optical absorption and emission in optical materials. Rev. Sci. Instrum. 89, 065109 (2018).

27. Garbil, R.; Sánchez-García, I.; Galán, H.; Perlado, J. M.; Cobos, J.; Davies, C.; Diaconu, D.: Stability studies of GANEX system under different irradiation conditions. EPJ Nucl. Sci. Technol. 5, 19 (2019).

28. Humphreys, J. C.; Hocken, D.; McLaughlin, W. L.; Dosimetry for High Dose Applications; Centre for Radiation Research, National Maeasurement Laboratory, National Bureau of Standards: Washington, USA, 1988.

29. Clough, R. L.: High-energy radiation and polymers: A review of commercial processes and emerging applications. Nucl. Instrum. Methods Phys. Res., B 185, 8 (2001).

30. Premnath, V.; Harris, W. H.; Jasty, M.; Merrill, E. W.: Gamma sterilization of UHMWPE articular implants: an analysis of the oxidation problem. Ultra High Molecular Weight Poly Ethylene. Biomaterials 17, 1741 (1996).

31. Sutula, L. C.; Collier, J. P.; Saum, K. A.; Currier, B. H.; Currier, J. H.; Sanford, W. M.; Mayor, M. B.; Wooding, R. E.; Sperling, D. K.; Williams, I. R.; et al.: The Otto Aufranc Award. Impact of gamma sterilization on clinical performance of polyethylene in the hip. Clin. Orthop. Relat. Res., 28 (1995).

32. Farkas, J.: Irradiation for better foods. Trends Food Sci. Technol. 17, 148 (2006).

33. Peterman, D.; Geist, A.; Mincher, B.; Modolo, G.; Galán, M. H.; Olson, L.; McDowell, R.: Performance of an i-SANEX System Based on a Water-Soluble BTP under Continuous Irradiation in a $\gamma^{-}$ Radiolysis Test Loop. Ind. Eng. Chem. Res. 55, 10427 (2016).

34. Mincher, B. J.; Precek, M.; Paulenova, A.: The redox chemistry of neptunium in $y$-irradiated aqueous nitric acid in the presence of an organic phase. J. Radioanal. Nucl. Chem. 308, 1005 (2015).

35. Mincher, B. J.; Mezyk, S. P.; Elias, G.; Groenewold, G. S.; Riddle, C. L.; Olson, L. G.: The Radiation Chemistry of CMPO: Part 1. Gamma Radiolysis. Solvent Extr. Ion Exch. 31, 715 (2013).

36. Mincher, B. J.: Degradation Issues in Aqueous Reprocessing Systems. In Comprehensive Nuclear Materials, Elsevier Ltd.: 2012; Vol. 5, pp 367-388.

37. Hubscher-Bruder, V.; Mogilireddy, V.; Michel, S.; Leoncini, A.; Huskens, J.; Verboom, W.; Galán, H.; Núñez, A.; Cobos, J.; Modolo, G.; Wilden, A.; Schmidt, H.; Charbonnel, M. C.; Guilbaud, P.; Boubals, N.: Behaviour of the extractant Me-TODGA upon gamma irradiation: quantification of degradation compounds and individual influences on complexation and extraction. New J. Chem. 41, 13700 (2017). 
38. Drader, J. A.; Boubals, N.; Cames, B.; Guillaumont, D.; Guilbaud, P.; Saint-Louis, G.; Berthon, L.: Radiolytic stability of $\mathrm{N}, \mathrm{N}$-dialkyl amide: effect on $\mathrm{Pu}(\mathrm{IV})$ complexes in solution. Dalton Trans. 47, 251 (2017).

39. Fernandez, A. F.; Brichard, B.; Berghmans, F.; Decreton, M.: Dose-rate dependencies in gamma-irradiated fiber Bragg grating filters. IEEE Trans. Nucl. Sci. 49, 2874 (2002).

40. Chu, R. D. H.; McLaughlin, W. L.; Miller, A.; Sharpe, P. H. G.: Dosimetry Systems for Use in 599 Radiation Processing. J. ICRU 8, 1 (2008).

600 41. ISO/ASTM; Practice for dosimetry in radiation processing; 52628:2013(E); Switzerland (2013).

601 42. Matthews, R. W.: Aqueous Chemical Dosimetry. Int. J. Appl. Radiat. Isot. 33, 1159 (1982).

602

603

604

605

606

607

608

609

610

611

612

613

614

43. ISO/ASTM; Standard Practice for Using the Fricke Dosimetry System; 51026:2015(E); Switzerland (2015).

44. ISO/ASTM; Standard Practice for Use of a Ceric-Cerous Sulfate Dosimetry System; 51205:2009(E); United States of America (2009).

45. Levine, H.; McLaughlin, W. L.; Miller, A.: Temperature and humidity effects on the gamma-ray response and stability of plastic and dyed plastic dosimeters. Radiat. Phys. Chem. 14, 551 (1979).

46. Malmbeck, R.; Magnusson, D.; Geist, A.: Modified diglycolamides for grouped actinide separation. J. Radioanal. Nucl. Chem. 314, 2531 (2017).

47. Zsabka, P.; Van Hecke, K.; Adriaensen, L.; Wilden, A.; Modolo, G.; Verwerft, M.; Binnemans, K.; Cardinaels, T.: Solvent Extraction of Am(III), $\mathrm{Cm}$ (III), and $\mathrm{Ln}(\mathrm{III})$ lons from Simulated Highly Active Raffinate Solutions by TODGA Diluted in Aliquat-336 Nitrate lonic Liquid. Solvent Extr. Ion Exch. 36, 519 (2018).

48. Zsabka, P.; Van Hecke, K.; Wilden, A.; Modolo, G.; Verwerft, M.; Binnemans, K.; Cardinaels, T.: Selective Extraction of Americium from Curium and the Lanthanides by the Lipophilic Ligand $\mathrm{CyMe}_{4} \mathrm{BTPhen}$ Dissolved in Aliquat-336 Nitrate Ionic Liquid. Solvent Extr. Ion Exch. 38, 194 (2020).

49. Zsabka, P.; Van Hecke, K.; Wilden, A.; Modolo, G.; Hupert, M.; Jespers, V.; Voorspoels, S.; Verwerft, M.; Binnemans, K.; Cardinaels, T.: Gamma Radiolysis of TODGA and $\mathrm{CyMe}_{4} \mathrm{BTPhen}$ in the Ionic Liquid Tri-n-Octylmethylammonium Nitrate. Solvent Extr. Ion Exch. 38, 212 (2020).

50. Fernandez, A.; Ooms, H.; Brichard, B.; Coeck, M.; Coenen, S.; Berghmans, F.; Decreton, M.: In SCK.CEN Gamma Irradiation Facilities for Radiation Tolerance Assessment, IEEE Radiation Effects Data Workshop, Phoenix, AZ, USA, IEEE: Phoenix, AZ, USA, 2002.

51. Lund, A.; Shiotani, M.: Applications of EPR in Radiation Research. 2014.

52. Anton, M.: Uncertainties in alanine/ESR dosimetry at the Physikalisch-Technische Bundesanstalt. Phys. Med. Biol. 51, 5419 (2006).

53. Anton, M.: Development of a secondary standard for the absorbed dose to water based on the alanine EPR dosimetry system. Appl. Radiat. Isot. 62, 779 (2005).

54. ASTM; Standard Practice for Monitoring the Calibration of Ultraviolet-Visible Spectrophotometers whose spectral Bandwidth does not Exceed 2 nm; E925-09 (Reapproved 2014); United States of America (2009).

55. Behrens, R.; Kowatari, M.; Hupe, O.: Secondary charged particle equilibrium in ${ }^{137} \mathrm{Cs}$ and ${ }^{60} \mathrm{Co}$ reference radiation fields. Radiat. Prot. Dosimet. 136, 168 (2009).

56. ISO/ASTM; Practice for use of a polymethylmethacrylate dosimetry system; 51276:2012(E); United States of America (2012).

57. ISO/ASTM; Practice for use of the alanine-EPR dosimetry system; 51607:2013; Switzerland (2013).

58. Fermvik, A.; Berthon, L.; Ekberg, C.; Englund, S.; Retegan, T.; Zorz, N.: Radiolysis of solvents containing C5-BTBP: identification of degradation products and their dependence on absorbed dose and dose rate. Dalton Trans., 6421 (2009).

59. Treguer, M.; de Cointet, C.; Remita, H.; Khatouri, J.; Mostafavi, M.; Amblard, J.; Belloni, J.; de Keyzer, R.: Dose Rate Effects on Radiolytic Synthesis of Gold-Silver Bimetallic Clusters in Solution. The Journal of Physical Chemistry B 102, 4310 (1998).

60. Chen, Y. P.; Liu, S. Y.; Yu, H. Q.; Yin, H.; Li, Q. R.: Radiation-induced degradation of methyl orange in aqueous solutions. Chemosphere 72, 532 (2008). 
645 61. Rodrigues, R. R.; Grynberg, S. E.; Ferreira, A. V.; Belo, L. C. M.; Squair, P. L.; Sousa, R. V.; 646 Sebastião, R. C. O.; Ribeiro, M. A.: Retrieval of GammaCell 220 irradiator isodose curves with MCNP 647 simulations and experimental measurements. Brazilian Journal of Physics 40, 120 (2010).

648 